\title{
Critical Success Factors in IT Projects-From the Practice of Polish Clients
}

\author{
Bartosz Wachnik \\ Warsaw University of Technology, \\ Faculty of Production Engineering \\ Institute of Organization of Production Systems \\ ul. Narbutta 85, 02-524 Warszawa, Poland \\ Email: bartek@wachnik.eu
}

\begin{abstract}
The article presents research results concerning critical success factors in IT projects consisting in ERP, CRM, BI and DM system implementations, completed between 2013 and 2017. The research stems from the need to update knowledge concerning critical success factors in projects completed in commercial enterprises. The research was carried out in medium and large enterprises implementing outsourcing-based projects. The research was conducted on five types of IT projects: standard implementation, upgrade, re-implementation, roll-out and implementation of a standard system with an add-on. The article will help better understand the influence of critical success factors on the implementation of IT projects during the whole project life cycle.
\end{abstract}

\section{INTRODUCTION}

$\mathrm{T}$ HE article belongs to a cycle [1] [2] of publications concerning critical success factors in IT projects consisting in the implementations of ERP, CRM, BI and DM management information systems completed based on outsourcing, defined by Auksztol [3] as a contract with an external body or internal organizational unit, set up in order to obtain IT services along with the supporting HR management, resource management and processes. The article presents the most recent research results on Critical Success Factors (CFSs) in Poland in the group of ERP, CRM, BI and DMS implementations in enterprises, thus updating Soja's research conducted in the group of ERP [4] system implementations. During the research, two important assumptions were made, differentiating this study from others:

1. According to Kerzner [5], research and analyses of projects completed based on outsourcing should consider the relations between the client and the supplier. We need to indicate, following Lichtenstein [6], that there is a partial incompatibility of interest between the client and the supplier, manifesting itself in a clear contradiction be- tween the maximization of the supplier's profit and the client's wish to complete the project at the lowest possible cost. My research [2] has confirmed Lichtenstein's observations-the goals and interests of a client and a supplier implementing an IT project are partially contradictory. For this reason, in my opinion, it is important to analyze CSFs separately from two different perspectives: the client's and the supplier's. The presented research results refer to the client's perspective.

2. Studying IT projects with the use of institutional economics, and especially the agent theory and the contractual theory, we can state that information asymmetry between the supplier and the client can influence project completion [7]. In my research, I carried out a series of studies employing qualitative methods indicating that information asymmetry between the supplier and the client influences the completion of IT projects during the entire project life cycle, i.e. at the preparatory stage (defining business requirements, selecting a system and a supplier), project completion stage and system operation (service level agreement-SLA) [8] [9]. Qualitative research led me to quantitative research concerning CSFs, indicating that information asymmetry is one of many CSFs requiring analysis. It is noteworthy that this factor was not accounted for in earlier research concerning CSFs, which can be seen from research results concerning ERP system implementations [10].

Research on CSFs in IT projects consisting in ERP, CRM, BI and DMS implementations in Poland was prompted by the following phenomena:

1. We observe the paradox of IT outsourcing, manifesting through a dynamic development of this concept in literature with a simultaneously high failure rate of IT projects completed based on outsourcing [11].

2 . The increasing technological and business complexity of IT projects, which leads to changes in CSFs.

The presented article consists of four sections. The literature studies chapter, concerning CSFs, is a synthesis of the problem as discussed by researches over the last 10 years. The methodology chapter presents research questions, the methods of data collection, a characteristic of the respondents and the research method. The chapter dedicated to research results presents data describing 
CSFs in Poland. In the last chapter, data obtained from the study is interpreted, limitations of the research are presented and further challenges in conducting CSF studies are indicated.

\section{Critical success factors in IT projects}

Bullen and Rockart [12] have defined CSF as "the limited number of areas in which satisfactory results will ensure successful competitive performance for the individual, department, or organization. CSFs are the few critical areas where 'things must go right' for the business to flourish and for the manager's goals to be attained". The increasing significance and the relevance of issues linked to the effectiveness of IT project implementation have contributed to the proliferation of publications containing many diverse approaches-and different research perspectives-of crucial success factors in IT projects. A noteworthy example is the cognitive taxonomy map of the axis of analysis of critical success factors in management information systems, mainly ERP systems, designed by Shaul and Tauber [10].

\section{Strategic-tactical axis.}

It groups critical success factors according to the completion of strategic and tactical plans of the enterprise where the implementation project is completed [13]. Tactical success factors cover factors concerning the technical configuration of IT systems and activities linked to project management carried out by the medium level of company management. Strategic success factors cover factors linked to the strategy of IT project completion carried out by the higher-level company management.

\section{Organization-end user axis.}

Esteves, Pastor [14] and Al-Mashari [15] indicate crucial success factors linked to economic and non-economic benefits of the organization's investment in management information systems. Researchers group them separately for the organization and for the end users.

\section{Public institutions-companies axis.}

Chang [16] identifies crucial success factors for IT projects completed in public institutions and companies. Also, Dyczkowski [17] indicates critical success factors in IT implementation projects in the public sphere in Poland. The character and nature of the organization influences the key success factors.

\section{National-global axis.}

According to Zhang [18], a unique nature of organizational culture and national culture of the organization where an IT project is implemented influence the final result. This type of research was also completed by Soja [19] in Poland, Colmenares [20] in Venezuela, Wu and Wang [21] in Taiwan, He and Brown [22] in China and Kamhawi in Bahrain [23].

\section{Endogenic-exogenic axis.}

Researchers point out that in defining the crucial success factors, it is important to provide for factors such as the competitiveness of the enterprise, the character of the industry, the level of innovativeness and the goals and interests of the external group of stake-holders [24]. Markus and Tanis [25], as well as Soh [26] stress that culture and enterprise management methods, its financial situation, size and organizational structure influence the crucial success factors.

\section{Developing-developed countries axis.}

Livermore and Ragowski [27] indicate differences in the completion of MIS implementation projects in different cultures. Ngai identifies and discusses critical success factors in IT projects completed both in developed and developing countries [28]. The specific character of crucial success factors in developed and developing countries is analyzed by many researchers, including Soja [19] in Poland, Colmenares [20] in Venezuela, Wu and Wang [29] in Taiwan, as well as He and Brown [22] in China.

\section{Cultural-technological axis.}

Estevez and Pastor [30] stress that critical success factors should provide for technical aspects of information management systems. Plant and Willcocks [31] indicate that even though an MIS implementation in an enterprise is not a technological, but mainly organizational event, we need to consider specific technological characteristics of software, including systems requirements for servers. On the opposite side of the axis, we can find cultural factors influencing an IT implementation project.

\section{Project life cycle-individual project phase axis.}

Umble stresses that critical success factors should be designed for individual phases of project life cycle, considering all the technical and organizational conditioning [32]. 


\section{Corporations-SME axis.}

Researchers classify critical success factors based on the organization size. Buonanno [33] presents separate groups of critical success factors both for small and medium-size enterprises. Loh and Koh identified two groups of critical success factors for IT projects of ERP implementations in small and medium-sized enterprises in Great Britain [34]. Wu and Wang [21] have carried out a comparative analysis of IT project completions in SMEs and large corporations, and identified two CSF groups.

\section{RESEARCH METHODOLOGY}

The main research goal is to identify the factors which influence the effectiveness of completing ERP, CRM, BI and DMS implementation projects based on outsourcing from the client's perspective. The research was completed based on the formula of four project-research steps. The use of three research methods in four steps stemmed from the wish to complete data triangulation and verify individual conclusions in subsequent projects.

Step 1. Literature analysis.

Step 2. Case studies allowing us to form a research hypothesis based on qualitative research, which will then be verified in Step 3.

The research hypothesis is:

$$
\text { H1: }
$$

Do the factors-predictors presented in Table 1 really influence the effectiveness of MIS implementation projects from the client's perspective?

According to the classic definition of IT project success, it is understood as completing the project within the planned budget, schedule and achieving the planned business goals, i.e. implementing the functional range.

Step 3. Quantitative research using structural equation modeling. The research goal is verifying the research hypothesis posed in Step 2.

In Step 3, in the period between January 2016 and March 2017, 127 clients-participants, using a website, completed a survey consisting of the following questions for each of the factors-predictors presented in Table 1: P1-6, P2-7, P3-5, P4-6, P5-6, P6-5, P7-5, P8-6, P9-5.

The research covered 61 observations concerning ERP systems, 26-BI systems, 25-DMS and 15-CRM systems. The studied sample of 127 IT projects contained the following number and structure of implementation types: 32
Table 1. Identified project success factors and their interpretation from the client's perspective.

\begin{tabular}{|c|l|}
\hline Predictor code & \multicolumn{1}{|c|}{ Factor-predictor } \\
\hline P1 & $\begin{array}{l}\text { Effective process of establishing functional requirements } \\
\text { for the implemented system }\end{array}$ \\
\hline P2 & Effective IT project management \\
\hline P3 & $\begin{array}{l}\text { Credible estimation and agreement with the supplier } \\
\text { regarding project parameters, i. e. project scope, budget } \\
\text { and schedule }\end{array}$ \\
\hline P4 & Competence and engagement of the client project group \\
\hline P5 & Choice and use of an IT implementation method \\
\hline P6 & Motivation of the client project group \\
\hline P7 & $\begin{array}{l}\text { Added value brought by the supplier into the implemented } \\
\text { system, i. e. knowledge concerning the functioning of } \\
\text { processes vs. the implemented functionalities }\end{array}$ \\
\hline P8 & $\begin{array}{l}\text { Information asymmetry between the supplier and the } \\
\text { client }\end{array}$ \\
\hline P9 & $\begin{array}{l}\text { Sharing knowledge about functionalities and technology } \\
\text { of the implemented system }\end{array}$ \\
\hline
\end{tabular}

standard implementations, 19 roll-outs, 31 reimplementations, 27 upgrades and 18 vertical system implementations. The research was carried out in medium and large enterprises, as classified by the EU. The analyzed projects were completed in the following types of enterprises: 25 - enterprises specializing in internet sale of FMCG products; 28-enterprises specializing in the installation and servicing of industrial machinery; 37enterprises from the life sciences industry; 5-transport and shipping enterprises; 16-IT enterprises; 8-retail enterprises; 8-food processing enterprises. All the enterprises showed profits in the year when the studied IT project was completed. The geographic distribution of the enterprises was as follows: Mazovia-25\%, Lesser Poland39\%, Greater Poland-17\% and Pokarpacie-19\%.

In Step 3, quantitative methods were applied, i. e. structural equation modeling, which allow for capturing the structure of relations between phenomena where hidden variables occur As structural equation modeling allows for modeling and testing complex phenomena, it becomes the preferred method of confirming or rejecting theoretical models using quantitative methods [35].

Structural equation modeling (SEM) is used to test the suitability of a given model to data and theory, understood as hypothetical relations between conceptually defined variables [36]. In the study, in order to test the consistency of the theoretical model, a structural equation analysis with the Partial Least Squares method (PLS) was carried out. The analytical model was created according to the reflexive model concept of latent characteristics. Each of the 10 latent characteristics in the model was represented by the observed indicators (50 altogether). The study used WarpPLS, which allows users to implement the PLS model [37] according to its requirements. 
Step 4. In-depth analytical workshops with a selected group of 10 respondents from the group of projects researched in Step 3. The respondents included project managers, board members and enterprise owners. The analytical workshops consisted in completing structured interviews with the respondents. One session with each respondent was completed, lasting between 1 to 3 hours each.

\section{RESEARCH RESULTS}

Coefficient of determination, otherwise known as the co-efficient of definiteness, or $\mathrm{R}^{2}$, is the measure of proportion of the variance in the dependent (explained) variable, which in our case is the evaluation of success in IT project completion representing projects completed with full success, understood as completed on budget, on time, and with all the functional requirements implemented. Independent variables are the nine predictors presented.

An analysis of the coefficients of model-to-data fit has indicated that the created theoretical reflexive model had a very good model-to-data fit.

The Tennenhaus GoF (Goodness-of-Fit) index equaled 0.41 (ideally $>=0.36$ ), the SPR index equaled 0.89 (ideal$\mathrm{ly}=1$ ), the RSCR index equaled 0.98 (ideally $=1$ ), the SSR index equaled 0.89 (acceptable if $>=0.7$ ) and the NLBCDR index equaled 0.83 (acceptable if $>=0.7$ ). An analysis of the total collinearity index of the AFVIF predictors showed that the average collinearity equaled 1.17 (ideally $<=3.3$ ).

Fig. 1 presents the model layout. Structural equation analysis has revealed that the model was characterized by a very good model-to-data fit and its parameters were not affected by collinearity of variables. An analysis of coefficients of explained variable has shown that model 9 of latent variables accounted for $23 \%$ of variance in success factors (the adjusted index equaled 17\%). $77 \%$ were factors not considered in the study.

\section{Study results interpretation}

The presented results of both qualitative and quantitative research on CSF, which influence the effectiveness of outsourcing-based ERP, CRM, BI and DMS implementation projects from the client's perspective, allow us to formulate the following key conclusions.

In the group of analyzed factors-predictors, we can differentiate between two groups: the first group is directly correlated with project success, while the second group is negatively correlated with project success. Below, a group of seven factors positively correlated with project success, the so-called CSFs, is described.

First of all, the SEM analysis has shown that the strongest factor-predictor influencing project success was effective project management. In-depth analytical workshops have shown that clients understand CSF as their project manager's care to keep the deadlines, complete the project on or under budget and achieve planned goals reflecting the implemented functionality.

The second most important factor-predictor influencing project success is a low level of information asymmetry between the supplier and the client, both at the

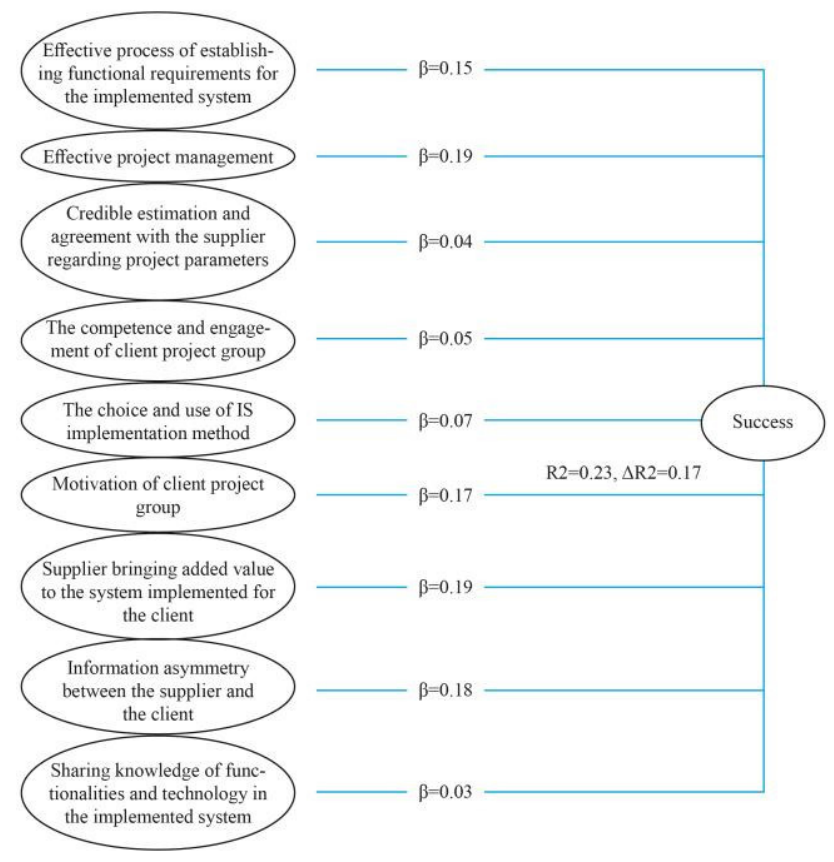

Figure 1. Model layout

preparatory stage and during implementation and operation. From a researcher's point of view, we need to stress that there are no precise methods of defining information asymmetry in IT projects and this parameter can only be estimated. Hence, the expression "low level of information asymmetry" declared by the respondents can be interpreted as client's relatively high level of knowledge concerning the implementation method, the methods of adapting systems, the knowledge of system operation, and the knowledge of how to minimize the TCO of the system, etc, in relation to the supplier, who naturally possesses more knowledge of the issues mentioned above.

We need to stress that the sub-chapter on literature research presented by Shaul and Tauber [10] does not mention any parameters reflecting the phenomenon of information asymmetry, understood as an information gap between the supplier and the client in an IT project. Analytical workshops have shown the client's concern that, as a consequence of the high level of information asym- 
metry and the phenomenon of negative selection, their project management costs will end up being higher than expected. To sum up, a significant novelty of the research results lay in identifying a high level of information asymmetry between the supplier and the client as a CSF.

The third most important factor-predictor influencing project success is the motivation of client's project group. In-depth analytical workshops have indicated that client's project group, i. e. project manager and key users, expected the enterprise management to provide a coherent and positive motivational system which would strengthen the project engagement. The respondents have pointed out that during project implementation they would spend the average of additional 2 to 4 hours in work, and thus expected the management to compensate them and motivate them to be engaged in project completion, mostly through economic benefits.

The fourth most important factor-predictor influencing project success is an effective process of establishing functional requirements for the implemented system, both at the preparatory stage aimed at selecting a system and a supplier, and the implementation stage, especially the functional analysis. As shown during analytical workshops, this factor-predictor depends mostly on client's organizational skill in obtaining and accumulating knowledge concerning the merits of the implemented systems.

The fifth most important factor-predictor influencing project success is the competence and engagement of client's project group. As demonstrated by in-depth analytical workshops, the competence of project group meant practical skills linked to project organization, the skill to pass on one's expectations for the system to the supplier in a precise manner, and skills linked to managing the project in critical situations. In-depth analytical workshops have indicated that the engagement of client's project group is understood as the engagement of key users on the client's side, who are responsible for designing business process modifications aimed at helping the company achieve a temporary competitive edge.

The sixth most important factor-predictor influencing project success was credibly evaluating and then agreeing on project parameters with the supplier. In-depth analytical workshops have indicated that respondents understood these parameters as: fixed implementation budget, license cost, detailed functional scope of the project and the TCO of the implemented system in the perspective of 3 to 6 years.

The seventh most important factor-predictor influencing project success is sharing the knowledge about functionalities and technologies in the implemented system. In-depth analytical workshops have shown that respond- ents understood this factor as a transfer of formal and informal knowledge, trainings and operating procedures.

Presented below is the group of factors negatively correlated with project success, the so-called critical failed factors.

The first most important factor-predictor negatively correlated with project success is the choice and use of system implementation method. In-depth analytical workshops have shown that the choice of implementation method from among Agile, Waterfall, Scrum and others did not positively influence project success.

The second most important factor-predictor negatively correlated with project success is bringing added value by the supplier to the system implemented for the client. During in-depth analytical workshops, respondents admitted that the knowledge and experience of supplier's consultants related to the implementation services was low. For this reason, they believed that, in practice, their supplier's consultants did not improve the functioning of their client's enterprise. The respondents admitted that these observations applied both to local and international companies. There are many CSFs critical to the success of an IT project. It is important that research concerning CSFs in IT projects is constantly updated due to the highpaced changes in technology and organization of IT projects, visible in the techniques, procedures and implementation methods. The changeability of implementation parameters may affect the structure of changing CSFs. There is not, however, a golden rule that would define the most important factors affecting project success. Successful projects do not necessarily include all the factors highlighted in this article. However, we should emphasize that the more CSFs there are, the higher the probability of success.

\section{CONCLUSIONS}

The research was completed between 2013 and 2017 on a sample of 971 projects in Poland, where the average percentage of ERP and CRM system implementation projects completed successfully in large enterprises equaled $49 \%$, and $48 \%$ in medium-sized enterprises, meaning that on average $50 \%$ of IT implementation projects ended in complete or partial failure [38]. In my opinion, the issues linked to analyzing failed projects from both the supplier's and the client's perspective are still noteworthy and it is important to analyze CSFs in outsourcing-based projects from both perspectives: the supplier's and the client's.

Only then will we be able to research what influences project success, not always understood equally by the client and the supplier. The CSFs diagnosed in the presented study are prevalently consistent with the axis of 
CSF analysis. It is noteworthy that quantitative research confirmed the hypothesis that a fuller picture of CSF in the selected group of IT projects completed through outsourcing should also consider the theories that belong to the new institutional economics, which describes business relations between suppliers and clients of the services provided. The phenomenon of information asymmetry between the supplier and the client constitutes a CSF influencing the success of an IT project. Despite the fact that it is impossible to measure the information gap between the supplier and the client in IT projects, the respondents indicated that a low level of information between the supplier and the client influences the success of project implementation.

The respondents understand low level of information asymmetry as knowledge, skills and experience possessed by the client concerning the implemented system, allowing for a more effective implementation of both the preparatory stage and project completion, which manifests itself through:

1. Defining precise functional requirements for an IT system.

2. Defining precise requirements for an IT system license.

3. Designing an implementation agreement and license purchase agreement that will ensure the completion of client's goals and interest.

4. Completing the project with the supplier so that it ends successfully.

5. Defining the total cost of ownership for the entire project life cycle.

6. Eliminating the phenomenon of moral hazard on the supplier's side.

7. Minimizing transaction costs on the client's side.

8. Partially eliminating the phenomenon of negative selection.

To sum up this synthetic presentation, I would like to stress that the research will be continued and the results will be published accordingly. I hope that by gathering and popularizing knowledge about CSFs of IT projects completed in commercial companies, it is possible to contribute directly to improving the effectiveness of completion process and management, as well as indirectly to the improving products and services that they are aimed at.

\section{REFERENCES}

[1] Wachnik B., 2015, "An Analysis of Effectiveness Factors in the Completion of it Projects-the supplier's Perspective," Scientific
Journals (Zeszyty Naukowe), Katowice: University of Economics in Katowice Publisher, vol. 234, pp. 1-12.

[2] Wachnik B., 2016, Wdrażanie Systemów Informatycznych Wspomagajacych Zarządzanie, Warszawa: PWE.

[3] Auksztol J., 2008, Outsourcing Informatyczny w Teorii i Praktyce Zarzadzania. Gdańsk: Wydawnictwo Uniwersytetu Gdańskiego.

[4] Soja P., 2006, "Success Factors in ERP Systems Implementations: Lessons from Practice," Journal of Enterprise Information Management, vol. 19, no. 6, pp. 646-661.

[5] Kerzner H., 2001, Strategic Planning for Project Management Using a Project Management Maturity Model. New York: John Wiley \& Sons..

[6] Lichtenstein Y., 2004, "Puzzles in Software Development Contracting," Communications of the ACM, vol. 47, no. 2, pp. 61-65, 2004, DOI: 10.1016/s0378-4754(00)00185-3.

[7] Dibbern J., T. Goles, R. Hirscheim, B. Jayatilaka, "Information Systems Outsourcing: A Survey and Analysis of the Literature," The Data Base for Advance in Information Systems, vol. 35, no. 4, pp. 6102, 2004 DOI: 10.1145/3051473.3051475.

[8] Wachnik B., 2014, "Reducing Information Asymmetry in IT Projectsaction Research Results," Scientific Journals (Zeszyty Naukowe), Katowice: University of Economics in Katowice Publisher, vol. 188, pp. 237-249.

[9] Wachnik B., 2015, "Information Asymmetry in Four IT Projects: The Client's Perspective. A Multiple Case Study," Information Systems in Management, vol. 2, pp. 155-168, DOI: 10.1145/2379776.2379777.

[10] Shaul L., D. Tauber, 2012, "CSFs in ERP Systems: Review of the Last Decade," ACM Computing Surveys, vol. 45, no. 4, pp. 1-39.

[11] Wachnik B., 2017, "An Analysis of ERP and CRM System Implementations in Poland Between 2013 and 2016," Journal of Economics and Management, DOI: 10.1111/jems.12187.

[12] Bullen C., J. Rockart, Eds, 1986, "A Primer on Critical Success Factors," The Rise of Managerial Computing: The Best of the Center for Information System Research, Homewood, Illinois: Dow JonesIrwin, pp. 383-423.

[13] Holland C., B. Light, N. Gibson, 1999, "A Critical Success Factors Model for ERP Implementation," IEEE Software, vol. 16, no. 3, pp. 30-36, DOI: 10.1109/IPCC.1999.799146.

[14] Esteves J., V. Bohorquez, 2007, “An Updated ERP Systems Annotated Bibliography: 2001-2005," Communications of the Association for Information Systems, vol. 19, no. 1, pp. 1-59, DOI: 10.1016/j.lrp.2007.

[15] Al-Mashari M., 2001, "Process Orientation Through Enterprise Resource Planning (ERP): A Review of Critical Issues," Knowledge and Process Management, vol. 8, no. 3, pp. 175-185, DOI: $10.1002 / \mathrm{kpm} .128$

[16] Chan J. W. K., 2008, "Prioritization the Critical Success Factors for ERP Implementation Project: Production Postponement Perspective," Industrial Engineering Research, vol. 5, no. 2, pp. 11-23.

[17] Dyczkowski M., 2008, "Wiedza o krytycznych czynnikach sukcesu jako istotny element poprawy efektywności przedsięwzięć informatycznych w sferze zarządzania publicznego," in Technologie Wiedzy w Zarzadzaniu Publicznym '07, J. Gołuchowski, A. Frączkiewicz-Wronka, Eds. Katowice: Prace Naukowe Akademii Ekonomicznej w Katowicach, vol. 7, pp. 291-309.

[18] Zhang Z., M. K. Lee, P. Huang, L. Zhang, X. Huang, 2005, "A Framework of ERP Systems Implementation Success in China: An Empirical Study," International Journal of Production Economics, vol. 98 , no. 1 , pp. 63-64.

[19] Soja P., "Difficulties in Enterprise System Implementation in Emerging Economies. Insight from an Exploratory Study in Poland," 2008, Information Technology for Development, vol. 14, no. 1, pp. 3151, DOI: $10.1002 /$ itdj. 20040.

[20] Colmenares L., 2004, "An Exploratory Study on the Critical Success Factors in the Implementation of Enterprise Resource Planning Systems in Venezuela," Journal of Information Systems and Technology Management, vol. 2, no. 2, pp. 167-187, DOI: 10.4301/10.4301\%2FS1807-17752007000100002.

[21] Wu J. H. , Y. M. Wang, 2003, "Enterprise Resource Planning Experience in Taiwan: An Empirical Study and Comparative Analysis," in Proc. of the 36th Hawaii International Conference on System Sciences, pp. 1-10. 
[22] He L., D. Brown, 2005, "The Adoption of ERP Applications in China," in Proc. of the 11th Americas Conference on Information Systems, pp. 284-292.

[23] Kamhawi E. M., "Critical Factors for Implementation Success of ERP Systems: An DEmpirical Investigation from Bahrain", International Journal of Enterprise Information Systems, DOI: 10.4018/IJEIS, vol. 3, no. 2, pp. 34-49, 2007.

[24] Bouchbout K., Z. Alimazighi, 2008, “A Framework for Identifying the Critical Factors Affecting the Decision to Adopt and Use Interorganizational Information Systems", World Academy of Science, Engineering and Technology, DOI: 10.1108/09504121011045809, vol. 43 , pp. $338-345$.

[25] Markus M. L., C. Tanis, 2000, "The Enterprise Systems Experiencefrom Adoption to Success," in Framing the Domains of IT Research: Glimpsing the Future Through the Past, Zmud R. W., Ed. Cincinnati: Pinnaflex Educational Resources Inc..

[26] Soh C., S. S. Kien, J. Tay-Yap, 2000, "Enterprise Resource Planning: Cultural Fits and Misfits: is ERP a Universal Solution?," Communications of the ACM, vol. 43, no. 4, pp. 47-51, DOI: 10.1016/s0378-4754(00)00185-3.

[27] Livermore C., A. Ragowsky, 2002, "ERP Systems Selection and Implementation: A Cross-cultural Approach," in Proc. of the 8th Americas Conference on Information Systems, pp. 1332-1339,.

[28] Ngai E. W., C. C. Law, F. K. Wat, 2008, "Examining the Critical Success Factors in the Adoption of Enterprise Resource Planning," Computers in Industry, vol. 59, no. 6, pp. 548-564.

[29] Wu J. H., Y. M. Wang, 2007, "Measuring ERP Success: the Criticalusers'Viewpoint of the ERP to Produce a Viable IS in the Organization," Computers in Human Behavior, vol. 23, no. 3, pp. 1582-1596.
[30] Esteves J., J. Pastor, 2000, "Towards the Unification of Critical Success Factors for ERP Implementation," in Proc. of the 10th Annual Business Information Technology (BIT) Conference, pp. 1-9.

[31] Plant R., L. Willcocks, 2007, "Critical Success Factors in International ERP Implementations: A Case Research Approach," Journal of Computer Information Systems, vol. 47, no. 3, pp. 60-70.

[32] Umble E. J., R. R. Haft, M. M. Umble, 2003, "Enterprise Resource Planning: Implementation Procedures and Critical Success Factors," European Journal of Operational Research, vol. 146, no. 2, pp. 241257.

[33] Buonanno G., P. Faverio, F. Pigni, A. Ravarini, D. Sciuto, M. Tagliavini, 2005, "Factors Affecting ERP System Adoption-A Comparative Analysis Between SMEs and Large Companies," Journal of Enterprise Information Management, vol. 18, no. 4, pp. 384-426, DOI: 10.1108/17410390810888697.

[34] Loh T., S. Koh, 2004, "Critical Elements for a Successful Enterprise Resource Planning Implementation in Small and Medium Sized Enterprises," International Journal of Production Research, vol. 2, no. 17, pp. 3433-3455, DOI: 10.1080/00207543.2017.1346318.

[35] Schumacher C. R., R.E. Lomaz, 2004, A Beginner's Guide to Structural Equation Modeling. Mahwah: Lawrence Erlbaum Associates, p. 7.

[36] Blunch N. J., 2008, Introduction to Structural Equation Modeling Using SPSS and AMOS. London: London Sage Publication.

[37] http://warppls.blogspot.co.uk/2009/12/welcome-to-warpplscommunity.html accessed: 20.04.2017.

[38] Wachnik B., 2017, "An Analysis of ERP and CRM System Implementations in Poland Between 2013 and 2016," Journal of Economics and Management, DOI: 10.1111/jems.12187. 